\title{
The Application of Multimedia and Network Technology on College Physical Education
}

\section{Xiaojun Wang}

Weinan Normal University, Physical College, Weinan, Shaanxi, 714000

Keywords: Colleges and universities; sports teaching; multimedia; network technology

\begin{abstract}
The 21st century is the information age. The penetration of network technology into all fields of society has facilitated people's lives and increased their work efficiency. All fields in society are facing reforms. In recent years, under the influence of quality education and curriculum reform, each school actively participates in education reform and timely adjusts its teaching activities. Multimedia and network technology have become important teaching methods at present, changing the traditional teaching methods and improving the teaching quality. Physical education is an important part of the teaching system in colleges and universities and fosters students' comprehensive development of physical fitness, skills and psychology. Therefore, it is necessary to improve the teaching quality of physical education by using multimedia and internet technology.
\end{abstract}

\section{Introduction}

Physical education is an important part of college education, but also an important part of cultivating all-round talents. With the rapid development of science and technology, the popularization and application of multimedia and network technology have penetrated into all fields of society, and the fields of education have also introduced multimedia and network technologies. The teaching of physical education in universities also changed the traditional teaching concept, took the initiative to introduce modern multimedia and network technology, enriched teaching content, stimulated students' interest in sports knowledge and sports skills, improved teaching quality and promoted the development of physical education.

\section{Multimedia technology and network technology overview}

Multimedia and network technology refers to the modern educational means of applying computer technology in education and management, especially the illustrations of multimedia technology and video images of activities. The application of multimedia and network technology in physical education curriculum is the reform of physical education in colleges and universities, which has an ideal teaching environment than the traditional teaching methods, and significantly improves the teaching quality and teaching efficiency of physical education curriculum.

Multimedia technology is multimedia computer technology, refers to the use of computer technology to comprehensively deal with a variety of media information, such as text, sound, images, graphics, animation, video, so that their organic together, with interactive computer technology. Therefore, multimedia technology is an organic combination of multiple media technologies. Like traditional media, multimedia technology possesses the ability of information exchange and communication. However, multimedia has the functions of human-computer interaction that traditional media do not have and can handle digital information.

Multi-media technology has many characteristics: First, multi-dimensional; can effectively handle the expansion and amplification of the information space, the input information to create and process, increase the performance of output information, and enrich its display. Second, the integration; multimedia technology can handle different media information and organic combination to form a complete multimedia information. In addition, it can integrate computer systems, audio equipment, video equipment, the various external devices organic combination of "sound, text, map, like" integrated processing. Third, interactive, multimedia technology with 
human-computer interaction capabilities, according to the needs of multimedia systems for control, selection and retrieval, so that multimedia users take the initiative rather than passive acceptance. Fourth, digital; multimedia technology is built on the basis of digital processing, the audio and video and other information are stored and processed in digital form. In addition, multimedia technology also has real-time, distribution and other characteristics.

\section{Problems of the traditional physical education model}

Traditional physical education is based on the teacher as the main body, using dictation, textbook teaching mode, has been emphasizing the dominant position of teachers, students completely ignore the main body of the classroom, students passively accept knowledge. A single teaching mode, boring classroom, is not conducive to the cultivation of students' innovative ability and practical ability.

The study of book knowledge can promote the development of students' cognition. However, over-reliance on textbooks and textbook knowledge as the basis will result in heavy theory and light practice. Knowledge itself is rich in content, but the language is abstract. The purpose of the language is to express the actual content in simple words. However, in the process of teaching, over - reliance on the content of textbooks can cause the students to wear out of school. Overemphasis on rational understanding, ignoring perceptual knowledge, and once considered rational is accurate, and perceptual knowledge is not reliable. Lack of humanity teaching, excessive pursuit of rationalization, abstraction, loss of knowledge should be contagious.

Teachers and students are the main body of the classroom, teaching and learning throughout the teaching process. Traditional teaching methods, over-emphasizing the dominant position of teachers, teachers are taught in the whole class, students passively accept knowledge, making students lose the initiative and creativity of learning. The whole teaching process, like the established computer program, is taught according to the pre-arranged lesson plan. The classroom atmosphere is boring, lacking in fun and closed and rigid.

\section{Multimedia and network technology in college physical education feasibility analysis}

In recent years, with the popularization and application of information technology, colleges and universities have also introduced a large number of hardware facilities, teachers are constantly upgrading the level, so colleges and universities have the hardware and software equipment can provide multimedia and network technology to provide appropriate support. Multimedia technology can clearly demonstrate the teaching content to meet the demonstration requirements of physical education. Audiovisual functions of multimedia courseware can fully mobilize the enthusiasm of students and stimulate the senses of students. Combination of multimedia and network technology, physical education teaching content includes theory and practice class, theory class includes sports overview, sports physiology, sports psychology, technical theory; practice class includes track and field, ball games and so on. Multimedia and Internet technology can provide rich pictures, images and information, enrich the content of college physical education, is conducive to the socialization of physical education. For example, sports-related electronic audio-visual, image and other materials through multimedia and network processing, the development of efficient multimedia courseware, physical education for colleges and universities to provide rich technical support, but also facilitate independent study under the students.

\section{Multimedia and network technology in college sports teaching application advantages}

Multi-media technology takes the physical education curriculum in the form of image and graphics to display the teaching content in three-dimensional and the expression style is more flexible. The network technology enriches the teaching content, so the multimedia and network technology have unique advantages in the teaching of colleges and universities.

Colleges and universities use multimedia and network technology to enrich the teaching 
resources, improve the physical education structure, improve the teaching efficiency and expand the teaching content. Many universities started using elective courses, online teaching and reporting results. The use of multimedia technology can abstract the image of the action displayed, the structure of the complex, high-speed demonstration of the action, the effect is excellent, multimedia technology can slow down the action, students can clearly perceive the composition of these actions and the formation of the corresponding The concept of easy to imitate and grasp later. In addition Yanshan University, Shenzhen University and other network-assisted physical education, such as the establishment of outdoor survival exercise. For students, the same faculty conditions, the use of multimedia and network technology, can simplify the learning process, and not subject to time and place restrictions, students can repeat learning, can make students better completion of the theoretical knowledge of sports learning and special learning, compared with the traditional teaching methods, improve learning efficiency.

The purpose of physical education in colleges and universities is to improve students 'learning ability, cultivate students' awareness of lifelong learning and promote the all-round development of talents. Multimedia technology can stimulate people's senses, making the vivid image of students, enhance the fun of the classroom and the expressiveness and appeal of the physical education content art. Multimedia teaching materials can fully demonstrate the strength of sports, beauty, so that students can really aware of the value of sports, stimulate students' curiosity. Effective use of network technology to integrate teaching resources, to achieve the sharing of learning resources, and to broaden students 'autonomous learning space, which have a good role in promoting students' learning enthusiasm and learning interest, and effectively promote the teaching objectives carry out.

The application of multimedia technology in physical education has changed the traditional teaching mode, students as the main body of the classroom to stimulate students' awareness of participation. To promote students' knowledge of sports and learning methods, under the application of network technology, the students as a whole participate in the exercise situation and evaluate the situation in an all-round way to promote the all-round and balanced development of students. Multimedia and network technology in college classroom teaching, you can deepen lifelong sports awareness, so that students take the initiative to participate in physical exercise.

\section{Improve multimedia and network technology in college PE classroom teaching effectiveness}

In today's rapid development of information technology, all fields of society are constantly undergoing reforms. Teaching concepts, teaching contents and teaching methods in the field of education are constantly changing with the wide application of modern educational technologies. College PE teachers should also actively meet the challenges they face, clarify the importance of multimedia and network technology, take the initiative to improve their professional skills and comprehensive literacy, keep abreast of the correct use of modern educational technology, and establish a correct teaching philosophy. In the process of teaching, teachers should change the traditional teaching idea, take the students as the main body of the class, give full play to students' learning initiative, pay attention to the combination of theory and practice, summarize teaching experience in time, use multimedia and network technology to assist teaching and innovate teaching mode. In addition, teachers should make full use of their spare time, keep abreast of advanced knowledge of professional skills and broaden their knowledge so as to lay a solid foundation for physical education in colleges and universities.

The school education administration department should clearly recognize the development trend of modern education, strengthen the construction of multimedia and network hardware facilities, and provide the necessary material basis for multimedia and network technology teaching. Multimedia and network hardware facilities are more expensive. College physical education contents have definite requirements on the quality and quantity of multimedia and network equipment. Therefore, capital investment in multimedia and network hardware equipment is increased, and hardware support for multimedia and network technologies is improved. In addition, multimedia and network technologies used in PE teaching in colleges and universities are limited by the venue. Most of the equipment is fixed and limited, most of which are placed indoors, thus 
restraining outdoor teaching. Therefore, colleges and universities to increase hardware equipment at the same time improve the technical input, the introduction of high professional quality teachers.

Any teaching methods have advantages and disadvantages, so in the process of using, we must grasp the use of "degree." A single media technology can also have an adverse effect on teaching effectiveness. College PE teachers in the teaching process, according to different teaching content, using different media mix to optimize the media mix. Modern media technology with advanced technology and equipment, complex technical actions can be displayed in three-dimensional form, accurate and effective feedback of teaching content, to stimulate students 'interest in learning, but overuse can cause students' boredom, so in the teaching in the process, it is necessary to organically combine with traditional media and optimize the teaching process. The two work together to complement each other's strengths and bring forth new ideas. Media effectiveness can be truly demonstrated and teaching quality can be improved.

\section{Conclusion}

To sum up, multimedia and network technologies are widely used in college PE classroom teaching and have unique advantages over traditional education. This has enabled the scientification of higher education and effectively improved the teaching efficiency. Although there are many advantages in multimedia and network technology, there are still some problems in practice. Teachers and students need to work together to optimize the teaching mode of multimedia and network technology, speed up the reform of colleges and universities and promote the further development of physical education.

\section{References}

[1] Zhang Yingjie, Han Xibin, Yang Fang, Zhang Bing Teaching Design of Sports Multimedia Courseware Based on Internet [J] Sports Science 2001,5

[2] Wang Runping. Multimedia Technology in Physical Education in a number of thinking [J] Journal of Northwest Normal University (Natural Science) 2003,4

[3] Wei Jia multimedia technology in college sports teaching application research [J] Chifeng University Journal 2011,6 (6): 146-147 